\title{
Spatio-temporal distribution of seismic moment release near the source area of the 2011 Tohoku-Oki earthquake
}

\author{
Jing-Yi Lin ${ }^{1}$ and Wen-Nan $\mathrm{Wu}^{2}$ \\ ${ }^{1}$ Institute of Geophysics and Department of Earth Sciences, National Central University, \\ 300 Jhongda Road, Jhongli City, Taoyuan County 32001, Taiwan \\ ${ }^{2}$ Institute of Earth Sciences, Academia Sinica, Nankang, Taipei 11529, Taiwan
}

(Received December 29, 2011; Revised March 16, 2012; Accepted April 9, 2012; Online published January 28, 2013)

\begin{abstract}
To understand the generation mechanism of the 2011 Tohoku-Oki earthquake, we analyzed the spatial and temporal distribution of the cumulative seismic moment $\left(\Sigma M_{0}\right)$ for all earthquakes along the Japan Trench listed in the global centroid moment tensor catalog between January 1976 and November 2011. Three areas with distinct characteristics of $\Sigma M_{0}$ are identified: (1) in the 2011 Tohoku-Oki source area, the $\Sigma M_{0}$ released in the down-dip portion $(\geq 30 \mathrm{~km})$ was greater than that in the up-dip portion $(<30 \mathrm{~km})$ before the mainshock; (2) the $\Sigma M_{0}$ of the up-dip portion in the region where slow slip activity prevails is greater than that of the down-dip portion throughout the study period; (3) in the surroundings of the source area, where interplate coupling is relatively low and the largest foreshock occurred, values of $\Sigma M_{0}$ for the down-dip and up-dip portions are both intermediate. Our results show that a megathrust rupture could be generated by large accumulations of strain energy at the subduction interface, resulting from the differential strain energy released in the down-dip and updip portions during the interseismic interval. We propose that the variation pattern of $\Sigma M_{0}$ may offer spatial constraints for seismic hazard assessment in the future.
\end{abstract}

Key words: Seismic moment, Tohoku earthquake, seismogenic zone, Japan Trench.

\section{Introduction}

The Japan Trench, where the Pacific plate subducts beneath the Okhotsk plate at an average rate of approximately 8 to $8.5 \mathrm{~cm} /$ year (DeMets et al., 2010), has experienced numerous interplate earthquakes with a moment magnitude $\left(M_{\mathrm{W}}\right)$ of 7 to 8 (Sagiya, 2004; Ishibe and Shimazaki, 2009; Ozawa et al., 2011). The 2011 Tohoku-Oki earthquake, a $M_{\mathrm{W}} 9$ megathrust earthquake, occurred in this area. The earthquake generated an enormous tsunami that killed more than ten thousand people (Hirose et al., 2011; Maeda et al., 2011).

During the past several decades, various geophysical methods and datasets have been used to understand the mechanisms behind these devastating earthquakes, including seismic and geodetic ground motion datasets (Mazzotti et al., 2000; Kawasaki et al., 2001; Koyama et al., 2004; Hashimoto et al., 2009; Igarashi, 2010; Katsumata, 2011; Uchida and Matsuzawa, 2011), historical tsunami deposits (Minoura et al., 2001; Satake et al., 2008), aftershock distributions (Katsumata et al., 1995), and seafloor bathymetry (Umino et al., 1990; Tanioka et al., 1997; Tsuji et al., 2011). The most traditional method is to evaluate the coupling on the subduction thrust faults by calculating the ratio of the observed to the expected moment release rate (Ruff and Kanamori, 1980; Peterson and Seno, 1984; Pacheco

Copyright (C) The Society of Geomagnetism and Earth, Planetary and Space Sciences (SGEPSS); The Seismological Society of Japan; The Volcanological Society of Japan; The Geodetic Society of Japan; The Japanese Society for Planetary Sciences; TERRAPUB.

doi:10.5047/eps.2012.04.006 et al., 1993; Ohnaka, 2004; Oishi and Sato, 2007). However, some studies have obtained weak interplate coupling (20-40\%) (Peterson and Seno, 1984; Pacheco et al., 1993; Matsumoto et al., 2008), whereas others have shown strong coupling along the Japan Trench (Nishimura et al., 2004; Suwa et al., 2006; Hashimoto et al., 2009). This contradiction is probably the result of two major limitations in the estimation of the moment release rate. One is that the available earthquake history is often too short compared with the long and variable recurrence time of large earthquakes. Another is that summed moment release rates are sensitive to the assumed width of seismically-active zones (Sandiford, 2008). Several improvements have been proposed to remedy the above limitations (McCaffrey, 1997; Frohlich, 2007; Frohlich and Wetzel, 2007); however, the computation procedure still seems a little complicated.

Here, we would like to use a simple approach without any assumptions by examining the cumulative scalar seismic moment release (hereafter, $\Sigma M_{0}$ ) in and around the 2011 Tohoku-Oki earthquake rupture area. Specifically, we quantify the energy release of the earthquakes by summing their seismic moment release $\left(M_{0}\right)$ within a given time or space window and we investigate its spatio-temporal variation along the Japan subduction system. The magnitude of the $\Sigma M_{0}$ can be viewed as a first-order approximation to the regional changes of shear strain in response to earthquakes (Sykes and Jaumé, 1990). In our calculation, we used earthquakes listed in the GCMT catalog, including the interplate and intraplate earthquakes. We recognize that the principal contribution to $\Sigma M_{0}$ comes from the large earthquakes 
in the subduction seismogenic zone (Pacheco and Sykes, 1992). Hence, we consider our result to be representative for the study of the seismogenic behavior of the subduction area. Our purpose has been simply to obtain the evolution pattern of $\Sigma M_{0}$ prior to the occurrence of large earthquakes, for providing an additional tool for seismic hazard assessment, even if the duration of our current seismic record is too short compared with a complete cycle of large earthquakes.

\section{Data Processing}

\subsection{Seismic data acquisition}

We used the global centroid moment tensor (GCMT) catalog (http://www.globalcmt.org/CMTsearch.html) from 1 January 1976 to 30 November 2011 to compute the $\Sigma M_{0}$. The time span covers 34 years and nine months, including the interseismic and post-seismic periods of the 2011 Tohoku earthquake (Fig. 2).

\subsection{Up-dip portion and down-dip portion}

As shown in Fig. 1, most rupture zones of the major historic earthquakes are distributed along the plate boundary between the forearc and the oceanic crust, at depths shallower than $30 \mathrm{~km}$. The behavior of earthquakes seems to vary with depth. In addition, seismic tomographic images show that the depth of the forearc Moho along the Japan Trench is approximately $30 \mathrm{~km}$ (Zhao et al., 1994, 2011; Satoh et al., 2001; Miura et al., 2005; Shinohara et al., 2005; Huang et al., 2011), which suggests the possible location of the brittle-ductile transition zone. We therefore separate the earthquakes into up-dip $(<30 \mathrm{~km}$, near trench) and down-dip ( $\geq 30 \mathrm{~km}$ ) parts in the following analysis. Furthermore, the lateral variation of the depth of the forearc Moho (e.g., Nakajama and Hasegawa, 2006; Uchida et al., 2010) and the hypocenter location uncertainty might affect the classification of earthquakes and change our result. To take these factors into consideration, we will perform our calculation by taking different boundary depths for the determination of the up-dip and down-dip events. The results of using 20- and 40-km boundary depths will be presented in Section 3, and we will demonstrate that there are no significant differences between the results with 20,30 and 40 $\mathrm{km}$ as boundary depth.

\subsection{Along-strike segmentation of the 2011 Tohoku earthquake}

The focal mechanism of aftershocks of the 2011 Tohoku-Oki earthquake varies from the north to the south (Fig. 2(b)), which may relate to the tectonic heterogeneity and the source effect of the mainshock. We therefore divide the study area into five segments along the Japan Trench based on the faulting types of the aftershocks (Fig. 2).

The most striking feature of a comparison of the distribution of post- and pre-seismicity is that only one earthquake occurred in Segment A after the mainshock (Fig. 2(b)). Due to its great distance from the rupture area, this event may not belong to the 2011 Tohoku-Oki earthquake sequence. However, it is worthwhile noting that the $2003 M_{\mathrm{W}} 8.3$ Tokachi-Oki earthquake has ruptured this area (earthquake 6 in Fig. 2(a)). The significant contribution of this event to the calculation of $\Sigma M_{0}$ will be discussed in the next section.

Most aftershocks in Segment B have a similar focal mechanism, showing NE-SW thrusting. Segments C, D and E show a complex pattern of focal mechanisms, including both extensional and compressive earthquakes (Fig. 2). The focal mechanisms of the down-dip earthquakes indicate a NE-SW thrust-faulting system, whereas the earthquakes in the up-dip portion indicate an extensional-faulting component, with a $T$-axis oriented in a roughly E-W direction (Fig. 2(b)) (Kato et al., 2011). The absence of near-trench aftershocks is observed in Segment C. The source area of the 2011 Tohoku-Oki earthquake is located in Segment D, and numerous normal-faulting events have occurred in the outer-rise area. Few normal-faulting outer-rise events are observed in Segment E, and the near-trench area is characterized as the thrust-faulting events.

\section{Spatial and Temporal Variation of $\Sigma M_{0}$ \\ 3.1 General features of $\Sigma M_{0}$}

To obtain a first impression of the temporal pattern of $\Sigma M_{0}$ in our study area, we plot the $M_{0}$ for each event considered in our study (Fig. 3(a)) and its accumulation $\Sigma M_{0}$ for the down-dip, up-dip and whole areas, respectively (Figs. 3(b)-(d)). The abrupt increases of $\Sigma M_{0}$ were mainly caused by earthquakes of a magnitude equal to, or greater than, 7.0 (Fig. 3). Among the most evident increases, only a few were caused by earthquake at a depth greater than $30 \mathrm{~km}$; namely, the 1978 M 7.7 and the 2005 M 7.4 earthquakes (events 1 and 7 in Figs. 2 and 3). In order to compare the influence of different boundary depths in our calculations, the $\Sigma M_{0}$ distribution for boundary depths of 30, 20 and $40 \mathrm{~km}$ are plotted (Figs. 3(b)-(d)). It is obvious that the $\Sigma M_{0}$ distribution of all earthquakes is mainly dominated by the down-dip and up-dip earthquakes when the boundary depth is $20 \mathrm{~km}$ and $40 \mathrm{~km}$, respectively, (Figs. 3(c) and 3(d)). Otherwise, the $\Sigma M_{0}$ contributed from the down-dip, up-dip and whole areas can be visibly distinguished when the boundary depth is $30 \mathrm{~km}$ (Fig. 3(b)). This result shows us that the use of $30 \mathrm{~km}$ as the boundary depth is justifiable. It is obvious that in the up-dip portion, the $\Sigma M_{0}$ curve increases regularly with time, corresponding with the occurrence of large earthquakes (dotted line in Fig. 3(b)). In contrast, the most remarkable increase in the down-dip side (dashed line in Fig. 3(b)) was contributed by the 1978 earthquake (event 1), and the curve appears to remain stable afterward. Note, also, that two earthquakes also occurred at the down-dip portion after 1978 (events 7 and 9). Though their magnitude is almost as large as that of the 1978 event, their contribution to $\Sigma M_{0}$ seems small relative to the large amount of $\Sigma M_{0}$ calculated since 1976.

\subsection{Spatial variation of $\Sigma M_{0}$}

To examine the spatial distribution of $\Sigma M_{0}$, we divided the study area into $0.4 \times 0.4$ degree grids. The seismic moments of all earthquakes in the up-dip $(<30 \mathrm{~km})$ and downdip ( $\geq 30 \mathrm{~km}$ ) portions within each grid was summed, respectively (Figs. 4(a)-(b)).The seismic moments for events shallower than $30 \mathrm{~km}$ are, in general, continuously and homogeneously distributed all along the trench, except in the area of $36-38^{\circ} \mathrm{N}$ (Fig. 4(a)). In the former area, $\Sigma M_{0}$ reached as high as $10^{21} \mathrm{~N}-\mathrm{m}$, but only $10^{18} \mathrm{~N}-\mathrm{m}$ in the latter ares. The $\Sigma M_{0}$ of the down-dip area reveals a reverse distribution pattern, with a high $\Sigma M_{0}$ observed in the area 


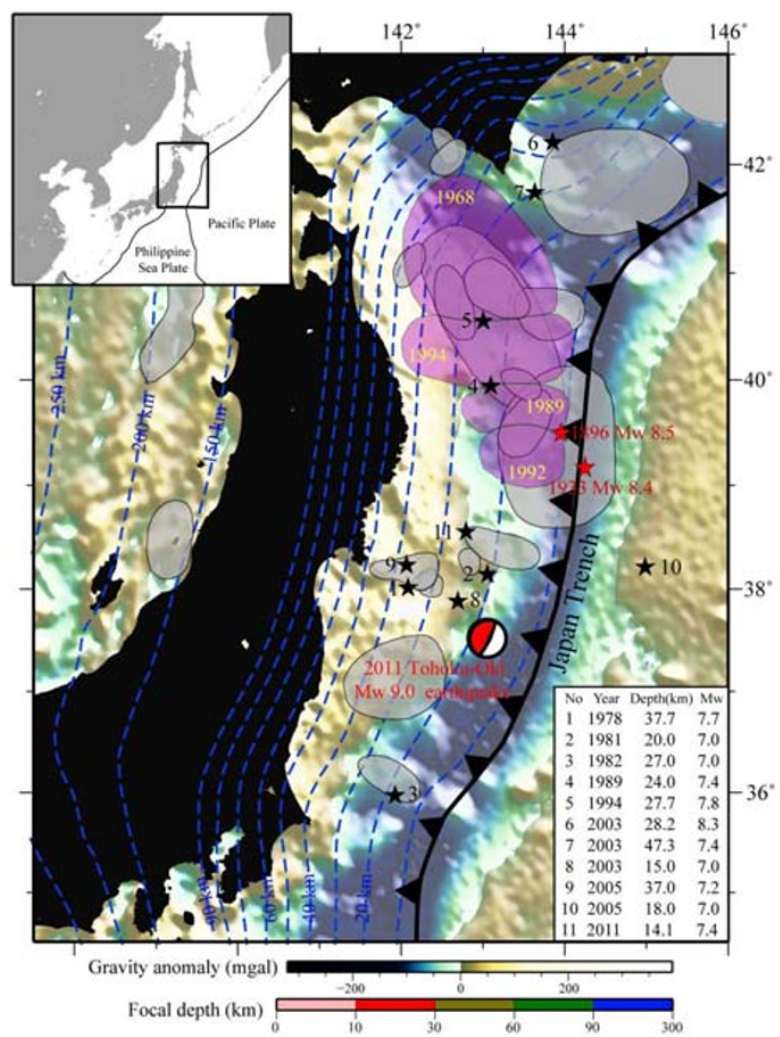

Fig. 1. Historical earthquake source areas along the Japan Trench and the distribution of aftershocks of the 2011 Tohoku earthquake. Gray areas indicate the distribution of the rupture areas of large shallow earthquakes (depth $\leq 60 \mathrm{~km}$ ) with a magnitude of 7 or greater (1926-1987) (Umino et al., 1990; Ammon et al., 2011). Purple contours indicate the source areas of the 1968 Takachi earthquake and the 1989, 1992 and 1994 ultra-slow earthquakes (Kawasaki et al., 2001). Beach balls show the focal mechanisms of the aftershocks of the $2011 M_{\mathrm{W}} 9.0$ Tohoku earthquake. Black stars are epicenters with a $M_{\mathrm{W}} \geq 7$ along the Japan Trench from the GCMT catalog for the period from January 1976 to November 2011. Blue dashed lines show the slab geometry (Nakajima and Hasegawa, 2006).
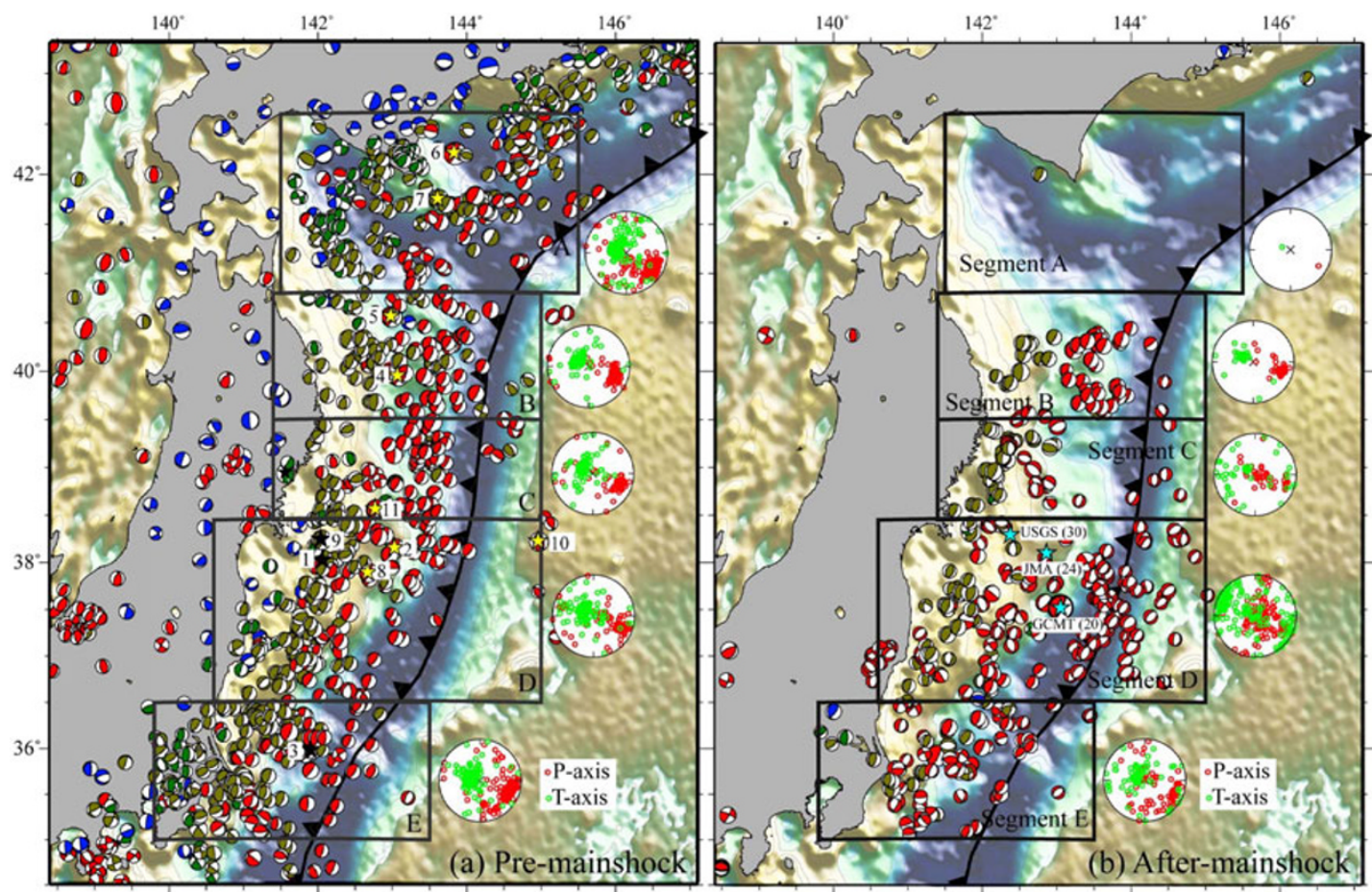

Fig. 2. The available focal mechanisms from the GCMT (a) before the 2011 Tohoku earthquake mainshock (1976/01/01 2011/03/11), and (b) after the mainshock (2011/03/11 2011/11/30) are plotted on the bathymetric map of the Japan subduction zone. The color scale corresponds to the depth range of the earthquakes. The stars in (a) are $M_{\mathrm{W}} \geq 7$ events, which are also shown in Fig. 1. Five segments along the Japan Trench in and around the source are identified based on the characteristics of the faulting types. Blue stars show the epicenter of the 2011 Tohoku-Oki mainshock determined by USGS, JMA and GCMT. The $P$ - and $T$-axis of the earthquakes in each segment are plotted. 


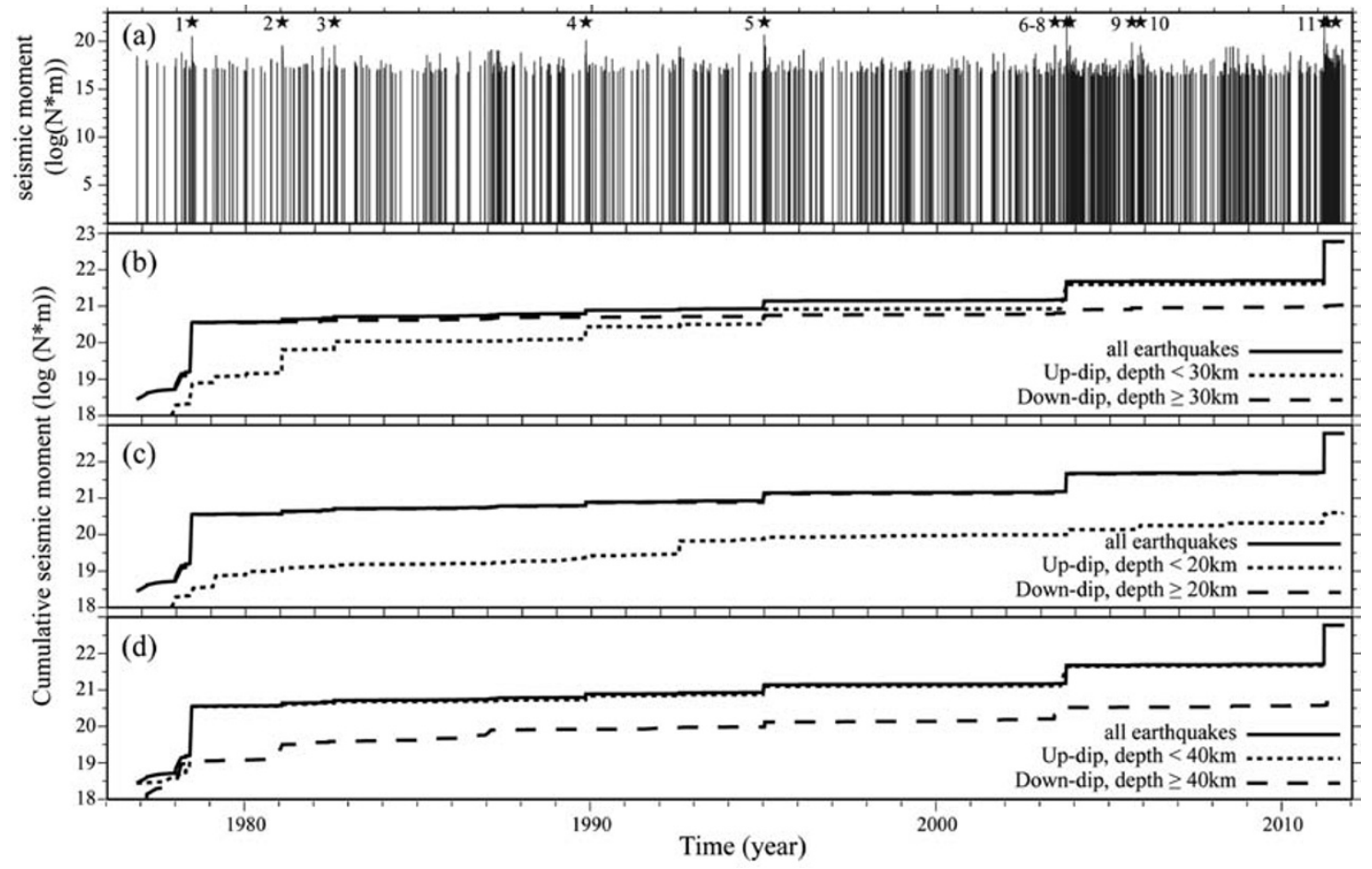

Fig. 3. (a) Scalar seismic moment for each event is plotted chronologically. Black stars with numbers are the earthquakes with a $M_{\mathrm{W}} \geq 7$ from the GCMT catalog, as shown in Fig. 1. (b) to (d) Cumulative seismic moment release for the whole study area (solid black line), the up-dip portion (dashed line) and the down-dip portion (dotted line) for boundary depths of 30, 20 and $40 \mathrm{~km}$, respectively.

of $36-38^{\circ} \mathrm{N}$ (Fig. 4(b)). This seismic moment release pattern indicates that a large amount of strain energy was released in the down-dip portion of the source area, and a small amount of energy was released in the up-dip side during the interseismic period.

To examine the effect of the boundary depth and show the robustness of our results, we repeat the calculation of $\Sigma M_{0}$ by changing the boundary depth to 20 and $40 \mathrm{~km}$, respectively (Figs. 4(c)-(d) and 4(e)-(f)). As shown in Fig. 4, the value of $\Sigma M_{0}$ in each grid changed with a different boundary depth. However, the spatial patterns of $\Sigma M_{0}$ still seem similar: a relatively-large seismic moment was released in the down-dip portion around the rupture zone of the 2011 Tohoku-Oki earthquake before the mainshock.

\subsection{Temporal variation of $\boldsymbol{\Sigma} \boldsymbol{M}_{\mathbf{0}}$}

The temporal pattern of $\Sigma M_{0}$ in the down-dip and updip portions for the five along-trench strike segments along the Japan Trench are shown in Fig. 5. The result obtained from all earthquakes shows that the values of $\Sigma M_{0}$ were the largest $\left(\sim 4.6 * 10^{20} \mathrm{~N}-\mathrm{m}\right)$ in the 2011 Tohoku earthquake source area (Segment D) between 1978 and 1994 (Fig. 5(c)) and remain stable until the occurrence of the mainshock. Meanwhile, with the obvious increases of $\Sigma M_{0}$ due to the moment release by three major interplate earthquakes in $1989\left(M_{\mathrm{W}} 7.4\right), 1992\left(M_{\mathrm{W}} 6.9\right)$ and $1994\left(M_{\mathrm{W}} 7.7\right)$, Segment B has the largest $\Sigma M_{0}\left(\sim 7.1 * 10^{20} \mathrm{~N}-\mathrm{m}\right)$ from 1994 to the occurrence of the 2003 Hokkaido earthquake. On the other hand, the magnitude of $\Sigma M_{0}$ in Segments A, C and D are nearly the same between 1976 and $2003\left(\sim 9.1 * 10^{19}\right.$ $\mathrm{N}-\mathrm{m})$. Then, the 2003 Hokkaido earthquake resulted in a significant increase of about $3 * 10^{21} \mathrm{~N}-\mathrm{m}$ in Segment A and resulted in Segment A having the largest $\Sigma M_{0}$ among all the segments before the 2011 Tohoku-Oki earthquake.

For the down-dip portion of the subduction zone (Fig. 5(b)), a one order difference in $\Sigma M_{0}$ exists between the two segments which have the largest $\Sigma M_{0}$ valueSegments A $\left(\sim 5.5 * 10^{19}\right)$ and $\mathrm{D}\left(\sim 4.5 * 10^{20} \mathrm{~N}-\mathrm{m}\right)-$ throughout the period from 1976 to 2003. Thus, the $\Sigma M_{0}$ of Segment A becomes close to the value of Segment D due to the 2003 Hokkaido earthquake. Consequently, Segments $\mathrm{A}$ and $\mathrm{D}$ have the largest $\Sigma M_{0}$ among all the segments throughout the period of 1976 to 2011. Meanwhile, their $\Sigma M_{0}$ in the up-dip portion were not always dominant (Fig. 5(a)). Similarly, although the $\Sigma M_{0}$ of Segment B was the highest in the period 1990 to 2003 in the up-dip part, its $\Sigma M_{0}$ in the up-dip portion is relatively small.

In Fig. 6, we compare the $\Sigma M_{0}$ of the five segments for the pre-mainshock period to obtain a more quantitative result. Before the Tohoku-Oki earthquake, Segments B, C and $\mathrm{E}$ have a similar $\Sigma M_{0}$ of about $4.5 * 10^{19} \mathrm{~N}-\mathrm{m}$ (equal to a $M_{\mathrm{W}} 7.1$ earthquake) in the down-dip part (Fig. 6(a)). However, the $\Sigma M_{0}$ in the up-dip portion of Segment B is about $6 * 10^{20} \mathrm{~N}$-m larger than that of Segments $\mathrm{C}$ and $\mathrm{E}$. This excess energy of Segment B is equivalent to an $M_{\mathrm{W}} 7.9$ earthquake. In Segment $\mathrm{A}$, the $\Sigma M_{0}$ of the up-dip portion is two orders higher than that $\Sigma M_{0}$ in the down-dip part (Fig. 6(a)). In Segment D, the source area of the 2011 mainshock, the $\Sigma M_{0}$ released in the down-dip part is about $3.4 * 10^{20} \mathrm{~N}$-m higher than in the up-dip part (Fig. 6(a)). A seismic moment of about $5 * 10^{22} \mathrm{~N}$-m is estimated for the 2011 mainshock, which is a hundred times the magnitude of the excess $\Sigma M_{0}$ in Segment D. The results calculated for the pre-seismic period of the 2003 Tokachi earthquake show that a relatively higher $\Sigma M_{0}$ exists both in Segments A and 


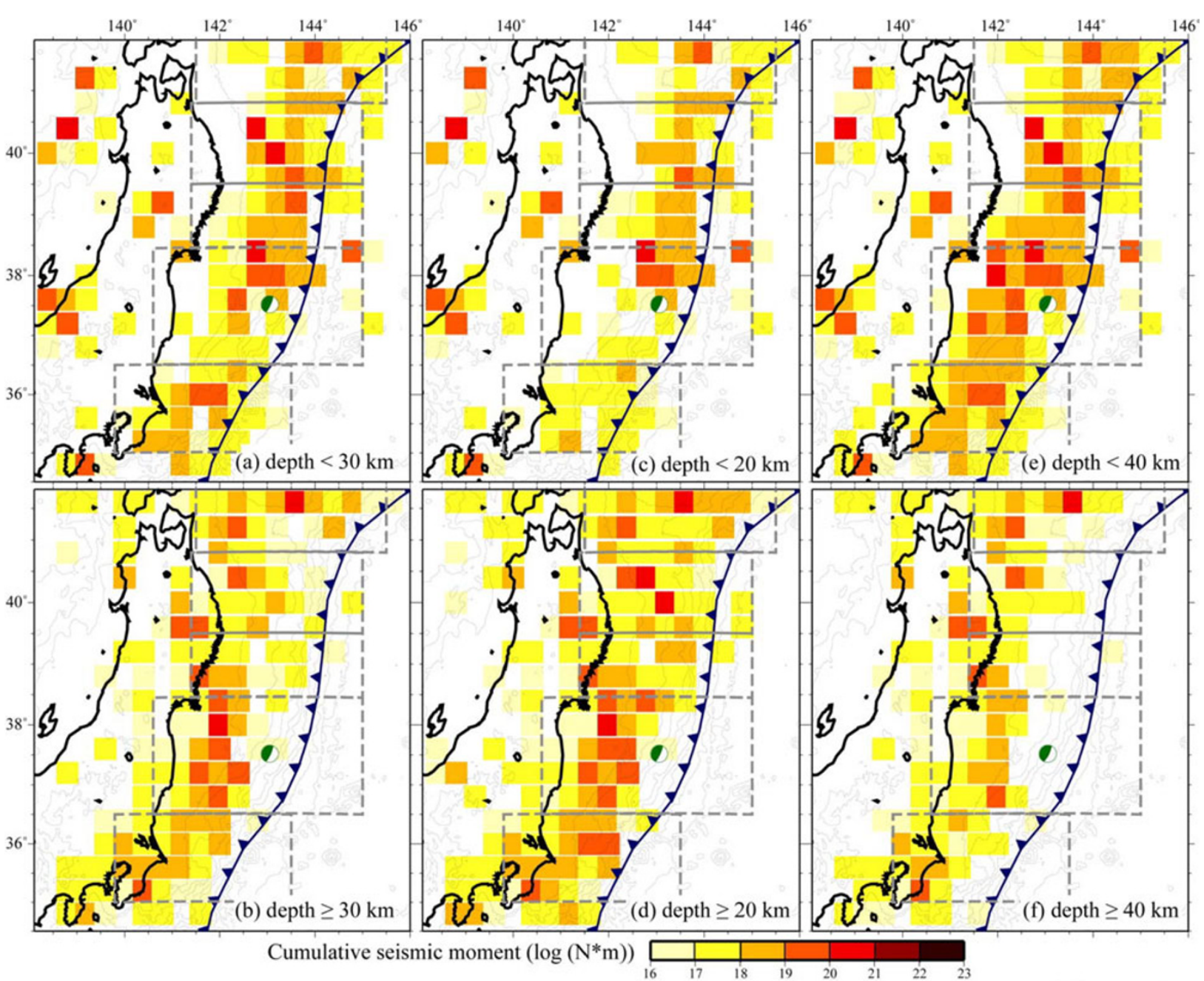

Fig. 4. Spatial distribution of the cumulative seismic moment release in the study area using the pre-seismicity in the up-dip, and down-dip, portions. In (a) and (b), the boundary depth is $30 \mathrm{~km}$; in (c)-(d) and (e)-(f) the boundary depth is 20 and $40 \mathrm{~km}$, respectively. The dashed rectangles show the position of the five segments.

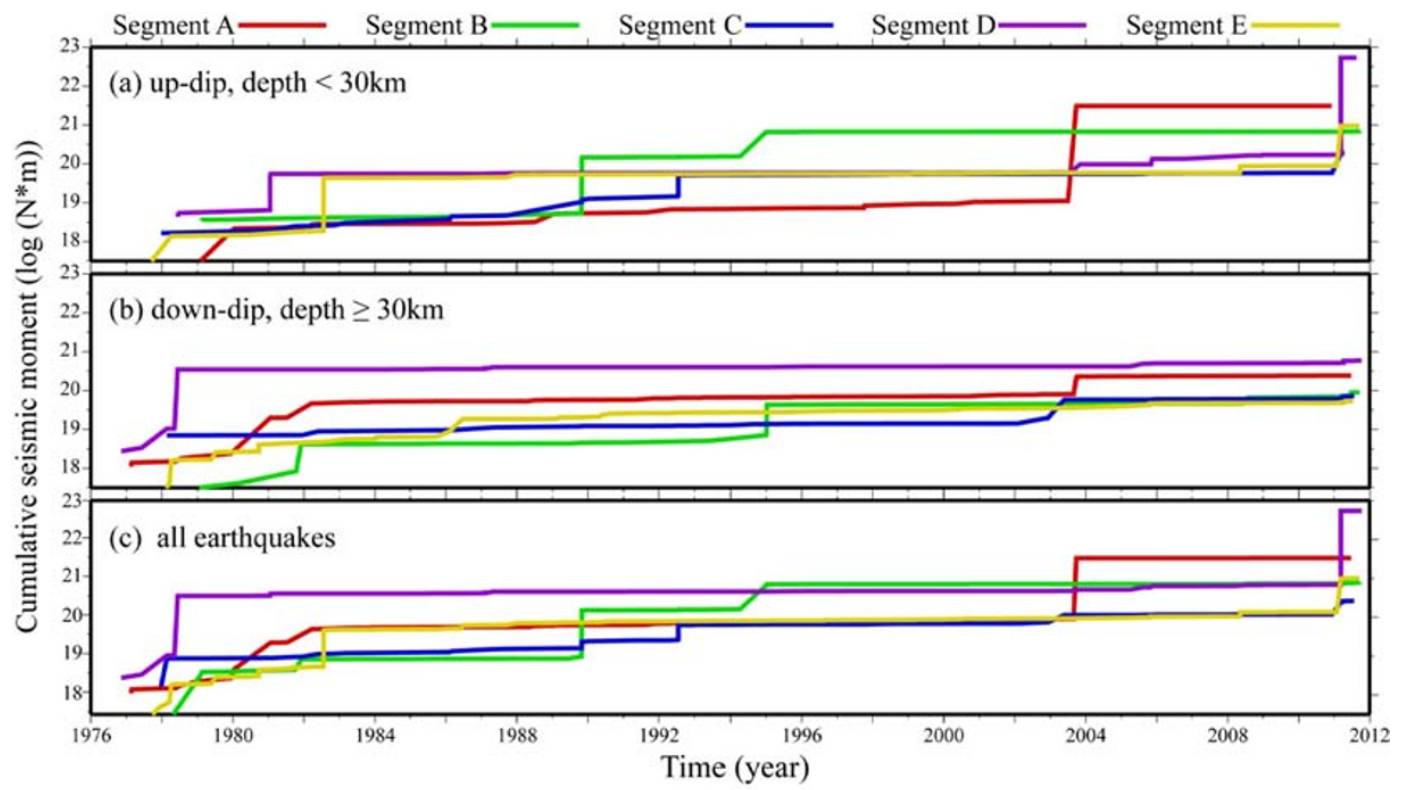

Fig. 5. Temporal evolution of the cumulative seismic moment release of the five segments defined in Fig. 2 for: (a) earthquakes shallower than 30 km (up-dip portion); (b) earthquakes deeper than $30 \mathrm{~km}$ (down-dip portion); (c) and all events in the area. 


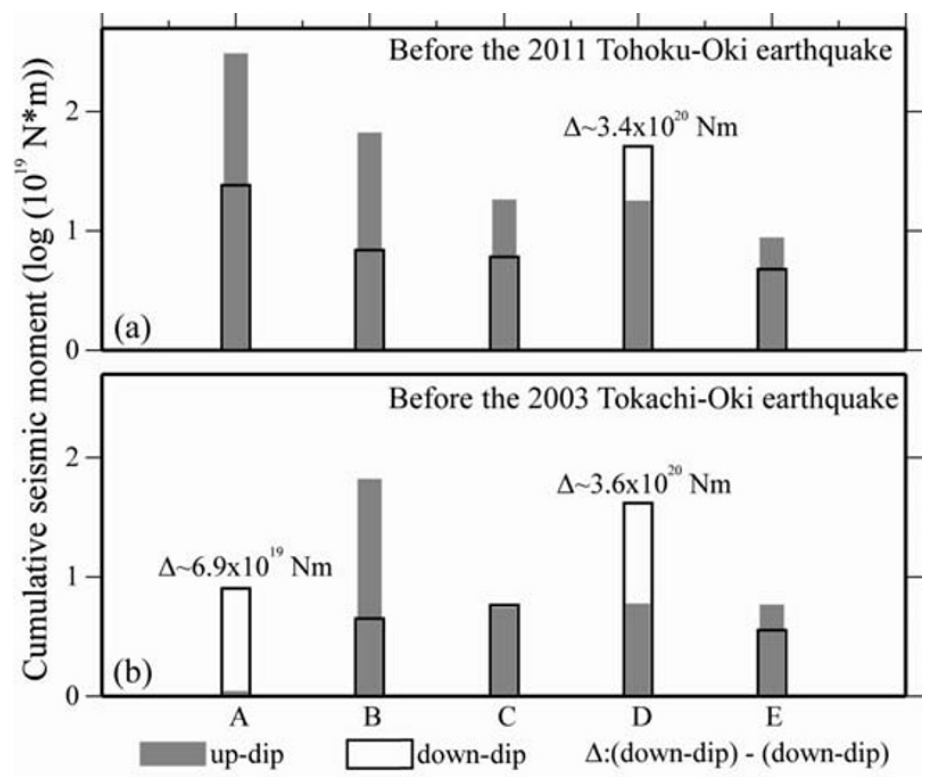

Fig. 6. Pre-mainshock cumulative seismic moment release of the five segments: (a) before the 2011 Tohoku-Oki earthquake; and (b) before the 2003 Tokachi-Oki earthquake. Gray and white bars show the cumulative seismic moment release in the up-dip and down-dip portion, respectively.

D, where megathrust events of magnitude greater than 8 occurred (Fig. 6(b)). The excess $\Sigma M_{0}$ of the down-dip part in the 2003 earthquake source area is estimated to be about $6.9 * 10^{19} \mathrm{~N}-\mathrm{m}$, which is smaller than that observed for the 2011 Tohoku-Oki earthquake area. This result suggests that a higher strain energy released in the down-dip than in the up-dip part, larger than the magnitude of the earthquake, could be induced in the up-dip portion.

To summarize, our observations show three distinct patterns of the $\Sigma M_{0}$ distribution with time and space: (1) in Segments A and D, where the 2003 Tokachi-Oki and the 2011 Tokoku-Oki earthquakes occurred, the strain energy in the down-dip area has been released more than in the updip area prior to the mainshock; (2) in Segment B, where the $1989\left(M_{\mathrm{W}} 7.4\right), 1992\left(M_{\mathrm{W}} 6.9\right)$ and $1994\left(M_{\mathrm{W}} 7.7\right)$ earthquakes occurred, strain energy in the up-dip area has been released more than that in the down-dip area throughout our study time; (3) in Segments C and E, where the largest foreshocks of the 2011 Tohoku-Oki earthquake $\left(M_{\mathrm{W}} 7.4\right)$ and the 1982 earthquake $\left(M_{\mathrm{W}} 7.0\right)$ occurred, the values of $\Sigma M_{0}$ in both the down-dip and up-dip areas are intermediate.

\section{Conceptual Mode of Megathrust Event}

On the basis of our observations and the results of previous studies, we extend a conceptual model originally from Lay et al. (2011a), regarding the possible stress variation and failure processes along the Japan Trench (Fig. 7), to explain three distinct $\Sigma M_{0}$ processes (Category 1 to 3) of the five rupture segments (Segments A to E) along the Japan Trench.

Many source inversion and geodetic modeling results have shown that the primary seismic moment contributions of the 2011 Tohoku mainshock were from the up-dip portion, possibly extending to the trench (Ammon et al., 2011; Iinuma et al., 2011; Lay et al., 2011b; Miyazaki et al., 2011) and that the source area was relatively strongly coupled (Mazzotti et al., 2000; Hashimoto et al., 2009;
Loveless and Meade, 2010; Uchida and Matsuzawa, 2011). We thus propose a first scenario to explain the occurrence of the 2011 Tohoku-Oki, and the 2003 Tokachi-Oki, earthquakes. If the up-dip region was completely locked, the energy released in the down-dip area may induce a large component of vertical upward slip and the strain energy could build up in the intersection area of the up- and downdip portions during the interseismic interval (Category 1, Fig. 7(a)). Once the friction on the subduction interface exceeds a critical value, strike-slip occurs resulting in the occurrence of a large earthquake (Category 1, Fig. 7(b)).

A second scenario is suggested based on our observations in Segment B (Category 1, Fig. 7(c)). By analyzing permanent GPS data, it has been suggested that the area located at the down-dip limit of the seismogenic zone off northern Tohoku and south of Hokkaido, extending from $39^{\circ} \mathrm{N}$ to $42^{\circ} \mathrm{N}$ (Segment B), has been decoupled (Mazzotti et al., 2000). Segment B coincides with the lower limit of the locked portion, which was ruptured during the $M_{\mathrm{W}}$ 7.6 Sanriku earthquake in December 1994 (Nakayama and Takeo, 1997) (Fig. 1). Thus, a large amount of energy was released by the 1994 mainshock and slow slips followed subsequently in the rupture area (Kawasaki et al., 2001), as expressed by the substantial seismic moment release in the up-dip portion shown in category 2 (Fig. 5(a)). Meanwhile, a significant part of the elastic energy is dissipated silently through the postseismic afterslip generated in the down-dip area (Heki et al., 1997; Mazzotti et al., 2000; Uchida et al., 2006). An excess of seismic slip in the down-dip area has also been suggested by geodetic data analysis (Hashimoto et al., 2009). As a result, the strain energy has been released aseismically in the down-dip portion of Segment B, which is reflected in the low $\Sigma M_{0}$ value in Figs. 4(a) and 5(b). In addition, the large seismic moment released by the previous large earthquakes and the subsequent slow slip in Segment $\mathrm{B}$ acted as a barrier to prevent the extension of both the 2011 Tohoku mainshock rupture and its aftershock activity 

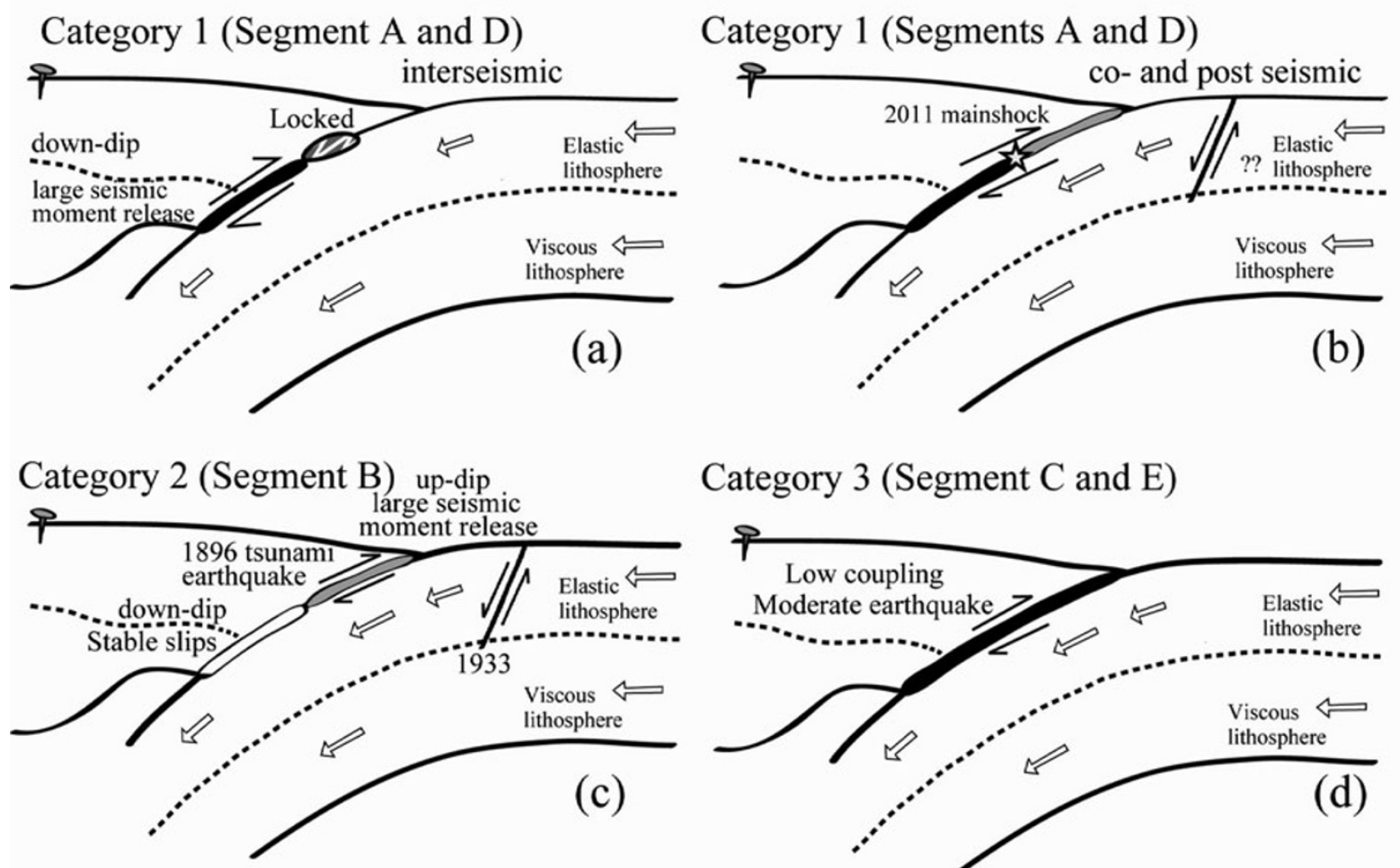

\section{Category 3 (Segment $\mathrm{C}$ and $\mathrm{E}$ )}

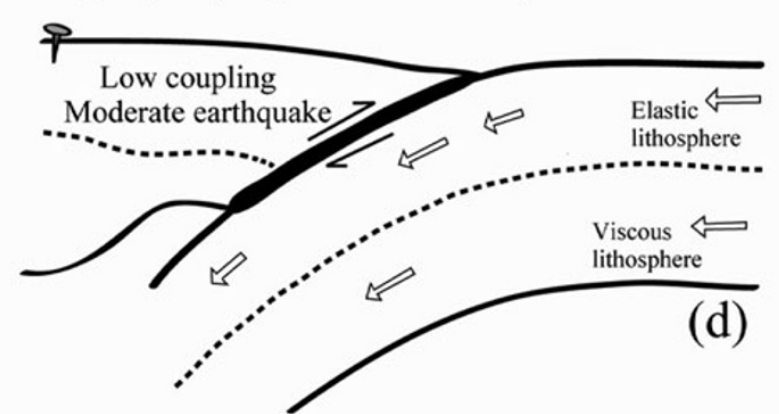

\begin{tabular}{|l|l|l|l|}
$\begin{array}{l}\text { Normal Rupture/Short Period } \\
\text { Seismic Waves }\end{array}$ & $\begin{array}{l}\text { Slow Rupture/Low Frequency } \\
\text { Seismic Waves }\end{array}$ \\
\hline
\end{tabular}

Fig. 7. Sketches of cross-sections for three distinct seismic characteristics along the three profiles in Fig. 2. Both (a) and (b) show the scenario for Category 1, and (c) and (d) show the scenarios for Categories 2 and 3, respectively, as defined in the text. The positions of the 1896 and 1933 earthquakes are shown in Fig. 1.

(Kosuga and Watanabe, 2011). This mechanism may explain why there have been only a few postseismic seismic moment increases in the northern part of this area (Fig. 2).

A third scenario corresponding to the Segments $\mathrm{C}$ and $\mathrm{E}$ (Fig. 7(d)), which are the northern and southern extended content of the 2011 Tohoku-Oki rupture area, respectively, has a relatively low coupling (Uchida and Matsuzawa, 2011) and small to intermediate values in $\Sigma M_{0}$ (Fig 5). Moreover, these two zones are characterized by moderate earthquakes $(M \sim 7)$ that repeat approximately every $\sim 20$ yr (Loveless and Meade, 2010), which may indicate a plate interface behavior only capable of producing moderate earthquakes. Additionally, two $M>7.0$ aftershocks of the 2011 Tohoku earthquake occurred approximately 20-30 min later at both the northern and southern edges of the rupture area, inducing an increase of up-dip seismic moment release in Segments C and E (Fig. 5(a)). These two segments may have been loaded by the mainshock (Miyazaki et al., 2011).

Here, it should be emphasized that although we cannot specifically estimate the timing and threshold of megathrust fault ruptures, our conceptual model provides plausible rupture scenarios in a spatial resolution for the occurrence of the 2011 Tohoku-Oki earthquake. More megathrust events in the worldwide subduction zones should be examined for a consistent pattern, as observed in this study. Furthermore, techniques which are more quantitative need to be applied in further studies to determine, more objectively and accurately, the difference between the spatial and temporal variations of up-and down-dip earthquakes before, and after, a large earthquake.

\section{Conclusions}

In summary, we integrate our results with the schematic cross-sections proposed by Lay et al. (2011a) regarding the possible stress variation and failure processes along the Japan Trench (Fig. 7). Three distinct seismic moment release processes (Categories 1 to 3 ) along five rupture segments were classified. Our results show that the great earthquakes, such as the $2011 M_{\mathrm{W}} 9.0$ Tohoku earthquake and the $2003 M_{\mathrm{W}} 8.3$ Hokkaido earthquake, could be produced in the first category. In this scenario, the energy was released in the down-dip portion but not in the up-dip portion, resulting in a large energy accumulation at their boundary prior to the mainshock. Our observations also show that the summation of GCMT catalog moments could be a potential tool for seismic hazard evaluation.

Acknowledgments. We thank the editor, Dr. Masanao Shinohara, and two anonymous reviewers for their helpful comments. Figures were prepared with the Generic Mapping Tool (GMT) software (Wessel and Smith, 1998). This study was under the financial support of the National Science Council of Taiwan (grant NSC100-2119-M-008-028). 


\section{References}

Ammon, C. J., T. Lay, H. Kanamori, and M. Cleveland, A rupture model of the 2011 off the Pacific coast of Tohoku Earthquake, Earth Planets Space, 63, 693-696, 2011.

DeMets, C., R. G. Gordon, and D. F. Argus, Geologically current plate motions, Geophys. J. Int., 181, 1-80, 2010.

Frohlich, C., Practical suggestions for assessing rates of seismic-moment release, Bull. Seismol. Soc. Am., 97, 1158-1166, 2007.

Frohlich, C. and L. R. Wetzel, Comparison of seismic moment release rates along different types of plate boundaries, Geophys. J. Int., 171, 909920, 2007.

Hashimoto, C., A. Noda, T. Sagiya, and M. Matsu'ura, Interplate seismogenic zones along the Kuril-Japan trench inferred from GPS data inversion, Nat. Geosci., 2, 141-144, 10.1038/ngeo421, 2009.

Heki, K., S. Miyazaki, and H. Tsuji, Silent fault slip following an interplate thrust earthquake at the Japan Trench, Nature, 386, 595-598, doi:10.1038/386595a0, 1997.

Hirose, F., K. Miyaoka, N. Hayashimoto, T. Yamazaki, and M. Nakamura, Outline of the 2011 off the Pacific coast of Tohoku Earthquake ( $M_{\mathrm{w}}$ 9.0)-Seismicity: Foreshocks, mainshock, aftershocks, and induced activity_, Earth Planets Space, 63, 513-518, 2011.

Huang, Z., D. Zhao, and L. Wang, Seismic heterogeneity and anisotropy of the Honshu arc from the Japan Trench to the Japan Sea, Geophys. J. Int., 184, 1428-1444, 2011.

Igarashi, T., Spatial changes of inter-plate coupling inferred from sequences of small repeating earthquakes in Japan, Geophys. Res. Lett., 37, L20304, 2010.

Iinuma, T., M. Ohzono, Y. Ohta, and S. Miura, Coseismic slip distribution of the 2011 off the Pacific coast of Tohoku Earthquake ( $M$ 9.0) estimated based on GPS data-Was the asperity in Miyagi-oki ruptured?, Earth Planets Space, 63, 643-648, 2011.

Ishibe, T. and K. Shimazaki, Seismicity in source regions of large interplate earthquakes around Japan and the characteristic earthquake model, Earth Planets Space, 61, 1041-1052, 2009.

Kato, T., Y. Terada, H. Nishimura, T. Nagai, and S. Koshimura, Tsunami records due to the 2010 Chile Earthquake observed by GPS buoys established along the Pacific coast of Japan, Earth Planets Space, 63, e5-e8, doi:10.5047/eps.2011.05.001, 2011.

Katsumata, K., Precursory seismic quiescence before the $\mathrm{M}(\mathrm{w})=8.3$ Tokachi-oki, Japan, earthquake on 26 September 2003 revealed by a re-examined earthquake catalog, J. Geophys. Res., 116, B10307, doi:10.1029/2010jb007964, 2011.

Katsumata, K., M. Ichiyanagi, M. Miwa, M. Kasahara, and H. Miyamachi, Aftershock distribution of the October 4, 1994 Mw8.3 Kurile islands earthquake determined by a local seismic network in Hokkaido, Japan, Geophys. Res. Lett., 22, 1321-1324, 1995.

Kawasaki, I., Y. Asai, and Y. Tamura, Space-time distribution of interplate moment release including slow earthquakes and the seismo-geodetic coupling in the Sanriku-oki region along the Japan trench, Tectonophysics, 330, 267-283, doi:10.1016/s0040-1951(00)00245-6, 2001.

Kosuga, M. and K. Watanabe, Seismic activity around the northern neighbor of the 2011 off the Pacific coast of Tohoku Earthquake with emphasis on a potentially large aftershock in the area, Earth Planets Space, 63, 719-723, 2011.

Koyama, J., N. V. Shestakov, and R. Honda, Strong ground motion recorded by high-rate sampling GPS at the closest site to the 2003 Tokachi-oki earthquake, Earth Planets Space, 56, 383-387, 2004.

Lay, T., C. J. Ammon, H. Kanamori, M. J. Kim, and L. Xue, Outer trenchslope faulting and the $2011 M_{\mathrm{w}} 9.0$ off the Pacific coast of Tohoku Earthquake, Earth Planets Space, 63, 713-718, 2011a.

Lay, T., C. J. Ammon, H. Kanamori, L. Xue, and M. J. Kim, Possible large near-trench slip during the $2011 M_{\mathrm{w}} 9.0$ off the Pacific coast of Tohoku Earthquake, Earth Planets Space, 63, 687-692, 2011b.

Loveless, J. P. and B. J. Meade, Geodetic imaging of plate motions, slip rates, and partitioning of deformation in Japan, J. Geophys. Res., 115, B02410, doi:10.1029/2008jb006248, 2010.

Maeda, T., T. Furumura, S. Sakai, and M. Shinohara, Significant tsunami observed at ocean-bottom pressure gauges during the 2011 off the $\mathrm{Pa}$ cific coast of Tohoku Earthquake, Earth Planets Space, 63, 803-808, 2011.

Matsumoto, Y., T. Ishikawa, M. Fujita, M. Sato, H. Saito, M. Mochizuki, T. Yabuki, and A. Asada, Weak interplate coupling beneath the subduction zone off Fukushima, NE Japan, inferred from GPS/acoustic seafloor geodetic observation, Earth Planets Space, 60, e9-e12, 2008.

Mazzotti, S., X. Le Pichon, P. Henry, and S. I. Miyazaki, Full interseismic locking of the Nankai and Japan-west Kurile subduction zones: An analysis of uniform elastic strain accumulation in Japan constrained by permanent GPS, J. Geophys. Res., 105, 13,159-13,177, 2000.

McCaffrey, R., Statistical significance of the seismic coupling coefficient, Bull. Seismol. Soc. Am., 87, 1069-1073, 1997.

Minoura, K., F. Imamura, D. Sugawara, Y. Kono, and T. Iwashita, The 869 Jogan tsunami deposit and recurrence interval of large-scale tsunami on the Pacific coast of northeast Japan, J. Nat. Disaster Sci., 23, 83-88, 2001.

Miura, S., N. Takahashi, A. Nakanishi, T. Tsuru, S. Kodaira, and Y. Kaneda, Structural characteristics off Miyagi forearc region, the Japan Trench seismogenic zone, deduced from a wideangle reflection and refraction study, Tectonophysics, 407, 165-188, doi:10.1016/j.tecto.2005.08.001, 2005.

Miyazaki, S., J. J. McGuire, and P. Segall, Seismic and aseismic fault slip before and during the 2011 off the Pacific coast of Tohoku Earthquake, Earth Planets Space, 63, 637-642, 2011.

Nakajima, J. and A. Hasegawa, Anomalous low-velocity zone and linear alignment of seismicity along it in the subducted Pacific slab beneath Kanto, Japan: Reactivation of subducted fracture zone?, Geophys. Res. Lett., 33, L16309, 2006

Nakayama, W. and M. Takeo, Slip history of the 1994 Sanriku-HarukaOki, Japan, earthquake deduced from strong-motion data, Bull. Seismol. Soc. Am., 87, 918-931, 1997.

Nishimura, T., T. Hirasawa, S. Miyazaki, T. Sagiya, T. Tada, S. Miura, and K. Tanaka, Temporal change of interplate coupling in northeastern Japan during 1995-2002 estimated from continuous GPS observations, Geophys. J. Int., 157, 901-916, 2004.

Ohnaka, M., Earthquake cycles and physical modeling of the process leading up to a large earthquake, Earth Planets Space, 56, 773-794, 2004.

Oishi, M. and T. Sato, Moment release budget at oblique convergence margin as revealed by the 2004 Sumatra-Andaman earthquake, Earth Planets Space, 59, 913-921, 2007.

Ozawa, S., T. Nishimura, H. Suito, T. Kobayashi, M. Tobita, and T. Imakiire, Coseismic and postseismic slip of the 2011 magnitude- 9 TohokuOki earthquake, Nature, 475, 373-376, 2011.

Pacheco, J. F. and L. R. Sykes, Seismic moment catalog of large shallow earthquakes, 1900 to 1989, Bull. Seismol. Soc. Am., 82, 1306-1349, 1992.

Pacheco, J. F., L. R. Sykes, and C. H. Scholz, Nature of seismic coupling along simple plate boundaries of the subduction type, J. Geophys. Res., 98, 14,133-14,159, 1993.

Peterson, E. T. and T. Seno, Factors affecting seismic moment release rates, J. Geophys. Res., 89, 10,233-10,248, 1984.

Ruff, L. and H. Kanamori, Seismicity and the subduction process, Phys. Earth Planet. Inter., 23, 240-252, 1980.

Sagiya, T., A decade of GEONET: 1994-2003-The continuous GPS observation in Japan and its impact on earthquake studies, Earth Planets Space, 56, xxix-xli, 2004.

Sandiford, M., Seismic moment release during slab rupture beneath the Banda Sea, Geophys. J. Int., 174, 659-671, 2008.

Satake, K., F. Nanayama, and S. Yamaki, Fault models of unusual tsunami in the 17th century along the Kuril trench, Earth Planets Space, 60, 925, 2008

Satoh, H., Y. Nishida, Y. Ogawa, M. Takada, and M. Uyeshima, Crust and upper mantle resistivity structure in the southwestern end of the Kuril Arc as revealed by the joint analysis of conventional MT and network MT data, Earth Planets Space, 53, 829-842, 2001.

Shinohara, M., R. Hino, T. Yoshizawa, M. Nishino, T. Sato, and K. Suyehiro, Hypocenter distribution of plate boundary zone off Fukushima, Japan, derived from ocean bottom seismometer data, Earth Planets Space, 57, 93-105, 2005.

Suwa, Y., S. Miura, A. Hasegawa, T. Sato, and K. Tachibana, Interplate coupling beneath NE Japan inferred from three-dimensional displacement field, J. Geophys. Res., 111, B04402, 2006.

Sykes, L. R. and S. C. Jaumé, Seismic activity on neighbouring faults as a long-term precursor to large earthquakes in the San Francisco Bay area, Nature, 348, 595-599, 1990.

Tanioka, Y., L. Ruff, and K. Satake, What controls the lateral variation of large earthquake occurrence along the Japan Trench?, Island Arc, 6 , 261-266, doi:10.1111/j.1440-1738.1997.tb00176.x, 1997.

Tsuji, T., Y. Ito, M. Kido, Y. Osada, H. Fujimoto, J. Ashi, M. Kinoshita, and T. Matsuoka, Potential tsunamigenic faults of the 2011 off the Pacific coast of Tohoku Earthquake, Earth Planets Space, 63, 831-834, 2011.

Uchida, N. and T. Matsuzawa, Coupling coefficient, hierarchical structure, and earthquake cycle for the source area of the 2011 off the Pacific coast 
of Tohoku earthquake inferred from small repeating earthquake data, Earth Planets Space, 63, 675-679, 2011.

Uchida, N., T. Matsuzawa, S. Hirahara, and A. Hasegawa, Small repeating earthquakes and interplate creep around the 2005 Miyagi-oki earthquake ( $M=7.2)$, Earth Planets Space, 58, 1577, 2006.

Uchida, N., S. H. Kirby, T. Okada, R. Hino, and A. Hasegawa, Supraslab earthquake clusters above the subduction plate boundary offshore Sanriku, Japan: seismogenesis in a graveyard of detached seamounts?, $J$. Geophys. Res., 115, B09308, doi:10.1029/2009JB006797, 2010.

Umino, N., A. Hasegawa, and A. Takagi, The relationship between seismicity patterns and fracture zones beneath northeastern Japan, Tohoku Geophys. J., 33, 149-162, 1990.
Wessel, P. and W. H. F. Smith, New, improved version of the Generic Mapping Tools Released, Eos Trans. AGU, 79, 579, 1998.

Zhao, D. P., A. Hasegawa, and H. Kanamori, Deep-Structure of Japan Subduction Zone as Derived from Local, Regional, and Teleseismic Events, J. Geophys. Res., 99, 22,313-22,329, 1994.

Zhao, D., Z. Huang, N. Umino, A. Hasegawa, and H. Kanamori, Structural heterogeneity in the megathrust zone and mechanism of the 2011 Tohoku-oki earthquake (Mw 9.0), Geophys. Res. Lett., 38, L17308, 2011.

J.-Y. Lin (e-mail: jylin@ncu.edu.tw) and W.-N. Wu 